\title{
Upper Eyelid Meibomian Gland Dysfunction is a Risk Factor for Dry Eye Symptoms Following Cataract Surgery in the Early Phase
}

\author{
Hisataka Fujimoto $\mathbb{D}^{1, *}$, Shintaro Ochi $\mathbb{D}^{2, *}$, Yasushi Inoue $\mathbb{D}^{2}$, Junichi Kiryu' \\ 'Department of Ophthalmology, Kawasaki Medical School, Kurashiki, 70I-0192, Okayama, Japan; ${ }^{2}$ Inoue Eye Clinic, Tamano, 706-00II, Okayama, \\ Japan \\ *These authors contributed equally to this work \\ Correspondence: Hisataka Fujimoto, Department of Ophthalmology, Kawasaki Medical School, 577 Matsushima, Kurashiki, 70I-0I92, Okayama, \\ Japan, Tel +8I-86-462-I I I , Fax +8I-86-462-I I99, Email fujimoto-h@med.kawasaki-m.ac.jp; Yasushi Inoue, Inoue Eye Clinic, I-I4-3I Uno, Tamano, \\ 706-00II, Okayama, Japan, Tel +8I-86-33I-1030, Fax+8I-86-33I-III4, Email inoue@oka.urban.ne.jp
}

Purpose: To evaluate perioperative dry eye (DE) syndrome and meibomian gland (MG) dysfunction parameters associated with cataract surgery-induced DE symptoms.

Patients and Methods: This retrospective, single-centered, observational study included 82 eyes of 43 patients without previous subjective DE symptoms, treatment, ocular comorbidities, and previous use of ophthalmic treatment, except for anti-allergic eye drops, who underwent uncomplicated cataract surgery. MG dropout, lid margin abnormality, meibum quality, meibum expressibility, MG orifice obstruction, ocular surface disease index, non-invasive tear break-up time, tear meniscus height, and Schirmer test score were measured at baseline and 1 month postoperatively. Multivariable logistic regression with generalized estimating equation models was used to determine the risk factors for cataract surgery-induced DE symptoms.

Results: Twenty-one patients had subjective DE symptoms 1 month following the cataract surgery. Preoperative and postoperative parameters, preoperative upper eyelid MG loss, and female sex (odds ratio [OR] 6.72, $\mathrm{P}=0.012$; OR 4.20, $\mathrm{P}=0.037$, respectively) were identified as risk factors for cataract surgery-induced DE symptoms.

Conclusion: Ocular parameters, including upper eyelid MG findings at baseline, were considered important in predicting persistent DE symptoms following cataract surgery.

Keywords: meibomian gland dysfunction, dry eye syndrome, retrospective, ocular surface disease index

\section{Introduction}

Cataract surgery with intraocular lens (IOL) implantation is one of the safest and most successful anterior segment surgeries; improved visual acuity is usually achieved. However, postoperative abnormalities of the tear film have been reported recently, including perioperative dry eye (DE). ${ }^{1}$ Some patients experience DE symptoms, including foreign body sensation, pain, and blurred vision even months or years following successful cataract surgery. ${ }^{2}$

DE symptoms related to cataract surgery are thought to be caused by various factors. Surgery can cause reduced tear break-up time (BUT), phototoxic damage during surgery, epithelial damage, decreased corneal sensitivity, and elevated inflammatory cytokines in tears, including matrix metalloproteinase (MMP) ${ }^{3-5}$ Moreover, the function of the meibomian gland (MG), the main organ maintaining the lipid layer of tear films, ${ }^{6}$ is altered after cataract surgery, resulting in DE symptoms induced by evaporative tear film. ${ }^{7}$

While the majority of the alterations occurring over the ocular surface following cataract surgery are considered to be transient, ${ }^{8-10}$ some patients experience cataract surgery-induced DE symptoms for longer periods. ${ }^{1}$ It is therefore important to characterize the DE risk factors following cataract surgery to minimize patient discomfort through diagnosis, thereby making intervention possible by the early identification of these risk factors. 
According to previous reports, the prevalence of post-cataract surgery DE was $55.7 \%{ }^{11}$ The incidence of after surgery DE in previously non-DE patients was $31.3 \% .{ }^{12}$ Among other monitored parameters, basal ocular surface disease index (OSDI) scores, female sex, and low TMH following surgery were significant risk factors, consistent with previous reports. ${ }^{13-15}$

In this study, in order to identify the ocular risk factors associated with early-onset cataract surgery-induced DE symptoms in patients without subjective DE symptoms and who did not use anti-DE ophthalmic solution (including artificial tears), we investigated the ocular characteristics, including MG, of patients who underwent cataract surgery by examining multiple parameters related to $\mathrm{DE}$ syndrome at baseline and 1 month postoperatively using a multivariable logistic regression analysis.

\section{Materials and Methods}

\section{Study Design}

This retrospective observational study included 43 patients with cataract. The study was approved by the Institutional Review Board of Kawasaki Medical School Hospital (approval number 5441-00). Informed consent was obtained from all the study participants. The study adhered to the tenets of the Declaration of Helsinki and was performed according to Good Clinical Practice (GCP). The study endpoints were evaluated by the researchers in a masked manner. This study did not involve patients or the public in its design, participant recruitment, or conduct.

\section{Data Collection}

The study observation period was from the date on which the patient started receiving care at the study site to the date on which the last data point was measured, which lasted from November 1, 2020 to August 31, 2021. To ensure uniform data collection, assessment, and compliance with the GCP, on-site training was conducted. Patient data records were selected based on the study inclusion and exclusion criteria. To minimize bias, eligible patients were enrolled consecutively.

The baseline data included age, sex, Schirmer's test ( $\mathrm{mm})$, ophthalmic solution use, and the following measures taken before cataract surgery: OSDI score, non-invasive BUT (NIBUT) measured by a video-corneal topographer Keratograph 5M (Oculus, Wetzlar, Germany) for each patient, and tear film instability related to DE measured and scored as DE grade (minimum, 0; maximum, 5) using the tear interferometer DR-1 $\alpha$ (Kowa, Tokyo, Japan). MG dysfunction (MGD) parameters measured by slit lamp examination, including fluorescein stain ${ }^{16}$ and infrared meibography on Keratograph 5M (Oculus, Wetzlar, Germany), and tear meniscus height (TMH) $(\mathrm{mm})$ at the postoperative visit (1 month after cataract surgery) were also collected. According to the 2016 Japanese Diagnostic Criteria for Dry Eye According, patients were considered to have DE when they had DE symptoms and decreased BUT ( $\leq 5$ seconds). ${ }^{17}$

MGD was diagnosed using the diagnostic criteria proposed by the MGD Working Group in Japan. ${ }^{18}$ MGD was diagnosed when both lid margin abnormalities and MG occlusion were present. ${ }^{19}$ Lid margin abnormalities (total lid margin abnormality) were considered to be present when at least two of the following conditions in at least one eye were satisfied: $\geq 2$ telangiectasias (vascularity of lid margin), lid margin irregularity (notching; irregular lid margin), and mucocutaneous junction (anteroplacement or retroplacement). ${ }^{19,20} \mathrm{MG}$ occlusion (total MG obstruction) was considered to be present when at least one eye had meibum secretions that were reduced when moderate pressure was applied with the thumb to the middle-third region of the upper eyelid (decrease in meibum expressibility) and $\geq 2$ gland orifices appeared to be plugged (MG orifice obstruction). ${ }^{19,20}$

The OSDI questionnaire, developed by the Outcomes Research Group at Allergan (Irvine, CA) was used to assess the DE symptoms. ${ }^{21}$ Briefly, the 12 items of the OSDI questionnaire were graded on scale 0 to 4 , of which 0 indicated no time; 1, sometimes; 2, half of the time; 3, most of the time; and 4, all of the time. The OSDI score was based on a 0 to 25 scale, and higher scores indicated more severe symptoms or discomfort. The OSDI score is finally multiplied by 4; the minimum and maximum possible scores are 0 and 100, respectively. To evaluate the ocular risk factors for cataract surgery-induced DE symptoms, we defined patients with an OSDI score $>0$ (except for blurred vision and poor vision since all cataract patients show visual impairment) at 1 month after cataract surgery as patients with cataract surgery- 
induced DE symptoms. ${ }^{19}$ The area of the MG structure was extracted by automatic threshold identification using ImageJ software and analyzed as described previously. ${ }^{22,23}$ Room temperature and humidity were maintained at $23-25^{\circ} \mathrm{C}$ and $30-40 \%$, respectively. For tear film lipid layer interferometry, the three videos captured using the tear interferometer DR$1 \alpha$ were analyzed in a masked manner. The classification and grading of tear lipid layer patterns has been described previously. ${ }^{11}$ DR-1 images were classified from grade 1 to 5 as follows: grade 1, slight gray color interference fringes and uniform distribution; grade 2, slight gray color interference fringes and non-uniform distribution; grade 3, mild colorful interference fringes and non-uniform distribution; grade 4, obvious colorful interference fringes and non-uniform distribution; and grade 5 , corneal surface partially exposed. ${ }^{11}$

TMH was obtained using anterior segment optical coherence tomography (AS-OCT) CASIA 2 (Tomey Corporation, Nagoya, Japan). Analysis software (Tomey Corporation, Nagoya, Japan) was used to identify and digitize the anterior corneal surfaces and tear meniscus areas. All digitization was confirmed by the researchers in a masked manner. Three measurements of the TMH were averaged.

The conjunctival redness in the nasal and temporal limbs were measured by Keratograph $5 \mathrm{M}$ (Oculus, Wetzlar, Germany) and scored between 0 (minimum) to 4 (maximum) based on the analysis software (Oculus, Wetzlar, Germany). ${ }^{24}$

All these ocular data were collected before and 1 month after the cataract surgery.

\section{Cataract Surgery}

All the cataract surgeries were performed by a single surgeon (Y.I.). Phacoemulsification with intraocular lens implantation was performed using the CENTURION ${ }^{\circledR}$ System (Alcon Laboratories, Inc., Fort Worth, Texas, USA) after a 2.2-mm clear corneal incision was made under topical anesthesia. An intraocular lens (ZCB00V; AMO Japan, Tokyo, Japan) was implanted in the capsular bag. Three days before surgery, topical $0.3 \%$ gatifloxacin was used four times daily. All the patients were prescribed $1.5 \%$ levofloxacin, $0.1 \%$ betamethasone, and $0.1 \%$ bromfenac eye drops four times daily from the day after the surgery until 1 month postoperatively according to the approved dose in Japan.

\section{Participants}

We retrospectively reviewed the clinical records (including video records) of 43 patients with cataract. We excluded patients with subjective DE symptoms (OSDI $>0$ ), using anti-DE ophthalmic solution (including artificial tears), and those with active ocular surface disorders, including epithelial disorders, such as Stevens-Johnson syndrome or ocular pemphigoid, infections, conjunctivitis, ocular inflammatory disease, and nasolacrimal duct obstruction. As an exception, patients with short BUT DE were included in the study, because such symptoms are often evident in patients with cataract, are clinically significant, and can be effectively targeted with DE therapy. Patients who need preoperative marking for toric IOL implantation were excluded because marking could affect the DE-related tear film dynamics. Cases of systemic diseases were also excluded, except for diabetes mellitus and systemic hypertension, which were controlled by the administration of oral medications. Individuals with a history of ocular surface surgery or those who were considered unsuitable by the principal investigator were also excluded from the study.

\section{Statistical Analysis}

The study was designed considering a sample size suitable for examining the risk factors for induction of DE after cataract surgery. Data distributions were assessed for normality using the Shapiro-Wilk test. Following the assumption that all the data on the outcomes of interest followed a parametric distribution, generalized estimating equation models $(\mathrm{GEE})^{25}$ were used to account for a possible correlation between the fellow eyes of the same patient. Risk factors for cataract surgery-induced DE symptoms were assessed using multivariable logistic regression analysis with GEE to account for a possible correlation between the fellow eyes of the same participant. With a sample size of 82 eyes, the power was greater than $80 \%$ and statistical significance was set at $P=0.05$. Two-sided $P$-values were determined in all the analyses, and statistical significance was set at $P<0.05$. All the statistical analyses were performed using SPSS version 25.0 (IBM Corp. Released 2017. IBM SPSS Statistics for Windows, version 25.0. Armonk, NY: IBM Corp. USA). 


\section{Results}

\section{Enrollment}

This study included the data of 82 eyes of 43 patients ( 22 men and 21 women; mean age, $75.70 \pm 4.83$ years) who underwent cataract surgery and in whom subjective DE symptoms were absent (OSDI=0). Ophthalmic solutions other than anti-allergic eye drops were not used by these patients. The duration of surgery was $6.06 \pm 0.89$ min and that of phacoemulsification was $51.59 \pm 14.04 \mathrm{~s}$.

After the cataract surgery, NIBUT significantly decreased compared with that before surgery $(P<0.001$, GEE; Table 1). Fluorescein staining score, OSDI score, dry eye grade by DR-1 $\alpha$, vascularity of lid margin (telangiectasia) score, irregular lid margin score, upper eyelid MG loss area (Figure 1), lower eyelid MG loss area (Figure 1), and redness in the temporal limbs significantly increased following the surgery compared with that before the surgery $(P<0.05$, GEE; Table 1).

Table I Comparison of Parameters in All the Included Eyes Measured Before and I Month After Cataract Surgery

\begin{tabular}{|c|c|c|c|c|c|}
\hline \multirow[t]{2}{*}{ Parameter } & \multicolumn{2}{|c|}{ Before Surgery } & \multicolumn{2}{|c|}{ After Surgery } & \multirow{2}{*}{$\begin{array}{l}\text { P-value (Before vs } \\
\text { After Surgery) }\end{array}$} \\
\hline & $\begin{array}{l}\text { Mean } \pm \\
\text { SD }\end{array}$ & $\begin{array}{c}95 \% \\
\text { Confidence } \\
\text { Interval }\end{array}$ & $\begin{array}{l}\text { Mean } \pm \\
\text { SD }\end{array}$ & $\begin{array}{c}95 \% \\
\text { Confidence } \\
\text { Interval }\end{array}$ & \\
\hline NIBUT (s) & $9.98 \pm 5.53$ & 8.76 to 11.20 & $7.57 \pm 4.69$ & 6.55 to 8.58 & 0.0010 \\
\hline Schirmer test $(\mathrm{mm})$ & $9.04 \pm 4.54$ & 8.03 to 10.01 & $\begin{array}{l}10.59 \pm \\
7.29\end{array}$ & 9.01 to 12.16 & 0.10 \\
\hline Fluorescein stein score $(0-9)^{11}$ & $0.28 \pm 0.59$ & 0.15 to 0.41 & $0.64 \pm 0.92$ & 0.45 to 0.85 & 0.022 \\
\hline OSDI score & $0.0 \pm 0.0$ & 0.0 to 0.0 & $1.90 \pm 4.01$ & 1.03 to 2.77 & $<0.001$ \\
\hline Dry eye grade by DR-I $\alpha(0-5)$ & $2.50 \pm 0.53$ & 2.39 to 2.62 & $2.74 \pm 0.48$ & 2.64 to 2.85 & 0.003 \\
\hline TMH (mm) & $0.27 \pm 0.16$ & 0.23 to 0.30 & $0.27 \pm 0.14$ & 0.24 to 0.30 & 0.91 \\
\hline $\begin{array}{l}\text { Vascularity of lid margin: telangiectasia }(0, \text { no; I, } \\
\text { yes) }\end{array}$ & $0.21 \pm 0.42$ & 0.11 to 0.26 & $0.38 \pm 0.49$ & 0.27 to 0.48 & 0.036 \\
\hline $\begin{array}{l}\text { Mucocutaneous junction: anteroplacement or } \\
\text { retroplacement ( } 0 \text {, no; I, yes) }\end{array}$ & $0.49 \pm 0.50$ & 0.38 to 0.60 & $0.48 \pm 0.50$ & 0.37 to 0.58 & 0.98 \\
\hline Irregular lid margin (0, no; I, yes) & $0.06 \pm 0.24$ & 0.01 to 0.11 & $0.18 \pm 0.39$ & 0.10 to 0.27 & 0.031 \\
\hline Total lid margin abnormality $(0, \text { no; I, yes })^{12}$ & $0.59 \pm 0.50$ & 0.48 to 0.69 & $0.73 \pm 0.45$ & 0.64 to 0.83 & 0.051 \\
\hline MG orifice obstruction ( 0, no; I, yes) & $0.66 \pm 0.47$ & 0.56 to 0.76 & $0.74 \pm 0.46$ & 0.65 to 0.84 & 0.30 \\
\hline Meibum expressibility decrease ( 0, no; I, yes) & $0.80 \pm 0.40$ & 0.72 to 0.89 & $0.73 \pm 0.45$ & 0.64 to 0.83 & 0.33 \\
\hline Total MG obstruction $(0, \text { no; I, yes) })^{12}$ & $0.62 \pm 0.49$ & 0.52 to 0.73 & $0.61 \pm 0.49$ & 0.50 to 0.72 & 0.49 \\
\hline Upper eyelid MG loss area (\%) & $73.9 \pm 4.3$ & 73.0 to 74.9 & $75.4 \pm 3.9$ & 74.6 to 76.3 & $<0.001$ \\
\hline Lower eyelid MG loss area (\%) & $57.7 \pm 11.1$ & 55.3 to 60.1 & $60.6 \pm 8.6$ & 58.8 to 62.5 & 0.002 \\
\hline Conjunctiva redness in nasal limbs $(0-4)$ & $1.20 \pm 0.5 \mathrm{I}$ & 1.10 to 1.30 & $1.21 \pm 0.46$ & 1.12 to 1.93 & 0.38 \\
\hline Conjunctiva redness in temporal limbs $(0-4)$ & $1.25 \pm 0.40$ & 1.17 to 1.33 & $1.36 \pm 0.36$ & 1.29 to 1.44 & 0.021 \\
\hline
\end{tabular}

Notes: All $P$-values were calculated using a generalized estimating equation model.

Abbreviations: MG, meibomian gland; MGD, meibomian gland dysfunction; NIBUT, non-invasive tear break-up time; OSDI, ocular surface disease index; SD, standard deviation; $\mathrm{TMH}$, tear meniscus height. 

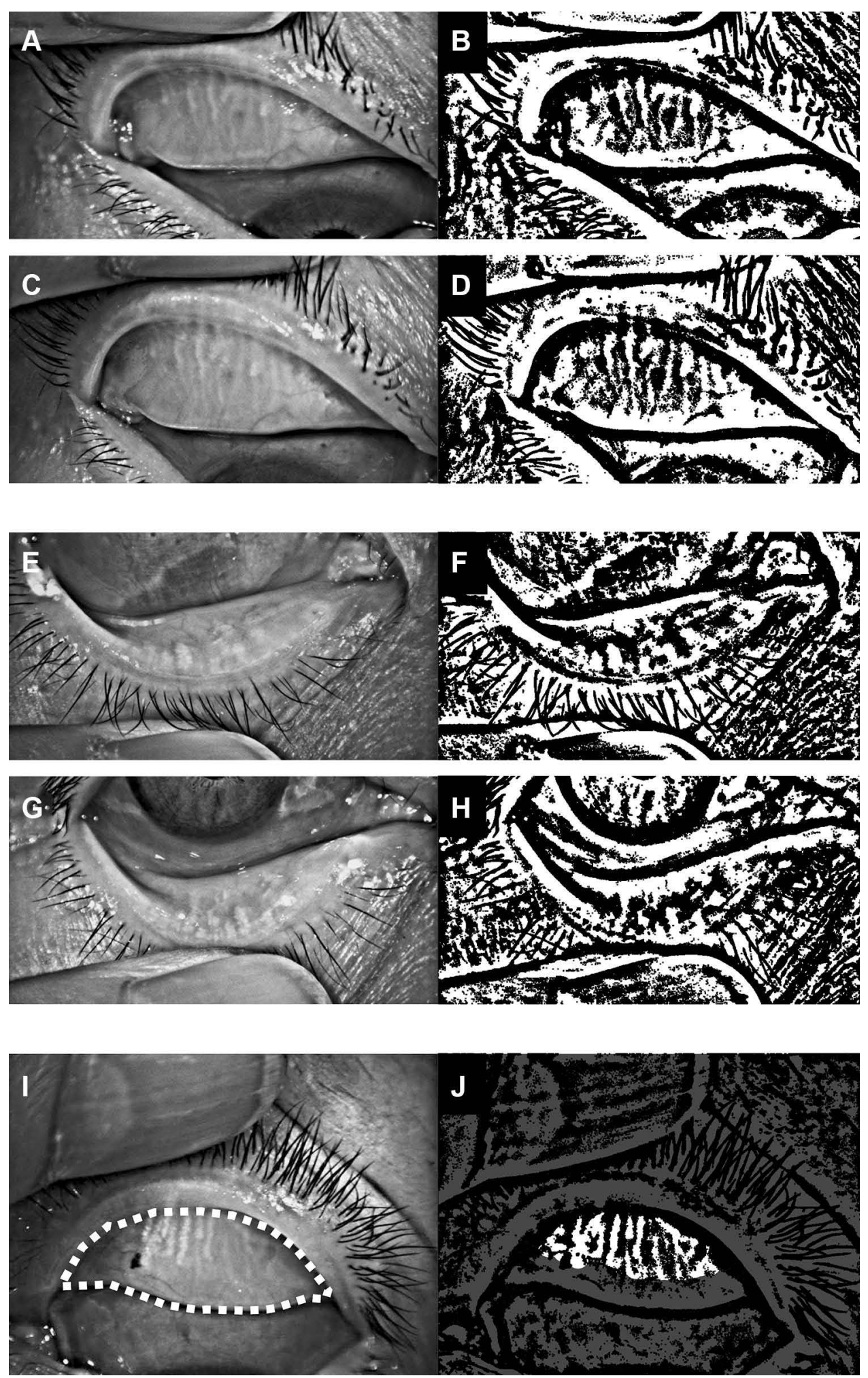

Figure I Representative measurements of upper and lower eyelid MG loss area (\%). Representative measurements of upper eyelid MG by meibography on Keratograph 5M before cataract surgery (A); digitized image from A (B); meibography image after cataract surgery (C); digitized image from C (D). Representative measurements for lower eyelid MG by meibography on Keratograph $5 M$ before cataract surgery $(\mathbf{E})$; digitized images from $E(\mathbf{F})$; meibography after cataract surgery $(\mathbf{G})$; digitized image from $G(\mathbf{H})$. Example of total analysis area (I) and detected MG area (J) used to compute the loss area (\%).

Abbreviation: MG, meibomian gland. 


\section{Demographics of Patients with and without Cataract Surgery-Induced DE Symptoms}

Sixty-one eyes of 35 patients (39 eyes in male patients and 22 in female patients; age, $75.50 \pm 4.67$ years) did not show any cataract surgery-induced subjective DE symptoms (OSDI $=0$ ), while 21 eyes of 14 patients did (OSDI $>0)(6$ eyes in male patients and 15 in female patients; age, $76.30 \pm 5.36$ years). The incidence of cataract surgery-induced subjective $\mathrm{DE}$ symptoms revealed a significant difference between the two sexes $(\mathrm{P}=0.002$; GEE, Table 2, Figure 2A).

Table 2 Comparison of the Background Parameters and the Parameters Before and I Month After Cataract Surgery in Patients with and without Cataract Surgery-Induced Subjective DE Symptom (OSDI >0)

\begin{tabular}{|c|c|c|c|c|c|c|}
\hline Label & \multicolumn{2}{|c|}{$\begin{array}{l}\text { With Cataract Surgery- } \\
\text { Induced Subjective DE } \\
\text { Symptom (2I Eyes) } \\
\text { Mean } \pm \text { SD }\end{array}$} & \multicolumn{2}{|c|}{$\begin{array}{l}\text { Without Cataract } \\
\text { Surgery-Induced } \\
\text { Subjective DE } \\
\text { Symptom (6I Eyes) } \\
\text { Mean } \pm \text { SD }\end{array}$} & \multicolumn{2}{|c|}{$\begin{array}{l}\text { P-value (with vs } \\
\text { Without Cataract } \\
\text { Surgery-Induced } \\
\text { Subjective DE } \\
\text { Symptom) }\end{array}$} \\
\hline Age (years) & \multicolumn{2}{|c|}{$76.30 \pm 5.36$} & \multicolumn{2}{|c|}{$75.50 \pm 4.67$} & \multicolumn{2}{|c|}{0.40} \\
\hline Female (\%)/Males & \multicolumn{2}{|c|}{$15(71.4 \%) / 6$} & \multicolumn{2}{|c|}{$22(36.1 \%) / 39$} & \multicolumn{2}{|c|}{0.002} \\
\hline Diabetes mellitus (\%) & \multicolumn{2}{|c|}{ I (4.8\%) } & \multicolumn{2}{|c|}{$17(27.9 \%)$} & \multicolumn{2}{|c|}{0.06} \\
\hline Hypertension (\%) & \multicolumn{2}{|c|}{7 (33.3\%) } & \multicolumn{2}{|c|}{31 (50.8\%) } & \multicolumn{2}{|c|}{0.41} \\
\hline \multirow[t]{2}{*}{ Duration of surgery (min) } & \multicolumn{2}{|c|}{$5.90 \pm 0.70$} & \multicolumn{2}{|c|}{$6.11 \pm 0.95$} & \multicolumn{2}{|c|}{0.29} \\
\hline & $\begin{array}{l}\text { Before } \\
\text { Surgery }\end{array}$ & $\begin{array}{l}\text { After } \\
\text { Surgery }\end{array}$ & $\begin{array}{l}\text { Before } \\
\text { Surgery }\end{array}$ & $\begin{array}{l}\text { After } \\
\text { Surgery }\end{array}$ & $\begin{array}{l}\text { Before } \\
\text { Surgery }\end{array}$ & $\begin{array}{l}\text { After } \\
\text { Surgery }\end{array}$ \\
\hline NIBUT (s) & $10.70 \pm 5.37$ & $7.11 \pm 4.22$ & $9.73 \pm 5.61$ & $7.72 \pm 4.86$ & 0.46 & 0.59 \\
\hline Schirmer test $(\mathrm{mm})$ & $8.76 \pm 4.54$ & $11.67 \pm 7.73$ & $9.15 \pm 4.58$ & $10.21 \pm 7.16$ & 0.91 & 0.39 \\
\hline Fluorescein stein score $(0-9)^{11}$ & $0.24 \pm 0.62$ & $0.76 \pm 0.89$ & $0.30 \pm 0.59$ & $0.61 \pm 0.94$ & 0.72 & 0.31 \\
\hline OSDI score & $0.0 \pm 0.0$ & $7.42 \pm 4.71$ & $0.0 \pm 0.0$ & $0.0 \pm 0.0$ & I & $<0.001$ \\
\hline Dry eye grade by DR-I $\alpha(0-5)$ & $2.67 \pm 0.64$ & $2.79 \pm 0.49$ & $2.44 \pm 0.47$ & $2.73 \pm 2.53$ & 0.23 & 0.17 \\
\hline TMH (mm) & $0.26 \pm 0.14$ & $0.22 \pm 0.09$ & $0.27 \pm 0.17$ & 0.29 to 0.15 & 0.98 & 0.016 \\
\hline Vascularity of lid margin: telangiectasia $(0$, no; I, yes) & $0.24 \pm 0.44$ & $0.43 \pm 0.51$ & $0.21 \pm 0.41$ & $0.36 \pm 0.48$ & 0.75 & 0.53 \\
\hline $\begin{array}{l}\text { Mucocutaneous junction: anteroplacement or } \\
\text { retroplacement ( } 0 \text {, no; I, yes) }\end{array}$ & $0.43 \pm 0.51$ & $0.48 \pm 0.52$ & $0.51 \pm 0.50$ & $0.49 \pm 0.50$ & 0.57 & 0.88 \\
\hline Irregular lid margin ( 0, no; I, yes) & $0.10 \pm 0.30$ & $0.19 \pm 0.40$ & $0.05 \pm 0.22$ & $0.18 \pm 0.39$ & 0.58 & 0.83 \\
\hline Total lid margin abnormality $(0, \text { no; I, yes })^{12}$ & $0.52 \pm 0.51$ & $0.76 \pm 0.43$ & $0.66 \pm 0.48$ & $0.72 \pm 0.45$ & 0.59 & 0.39 \\
\hline MG orifice obstruction ( 0, no; I, yes) & $0.52 \pm 0.51$ & $0.76 \pm 0.44$ & $0.70 \pm 0.46$ & $0.72 \pm 0.45$ & 0.25 & 0.89 \\
\hline Meibum expressibility decrease ( 0, no; I, yes) & $0.90 \pm 0.30$ & $0.90 \pm 0.30$ & $0.77 \pm 0.42$ & $0.67 \pm 0.47$ & 0.15 & 0.028 \\
\hline Total MG obstruction $(0, \text { no; I, yes })^{12}$ & $0.52 \pm 0.51$ & $0.71 \pm 0.46$ & $0.66 \pm 0.48$ & $0.57 \pm 0.50$ & 0.43 & 0.51 \\
\hline Upper eyelid MG loss area (\%) & $75.5 \pm 4.1$ & $76.8 \pm 4.2$ & $72.7 \pm 3.6$ & $74.9 \pm 3.8$ & 0.006 & 0.67 \\
\hline Lower eyelid MG loss area (\%) & $57.1 \pm 11.0$ & $61.5 \pm 5.4$ & $57.9 \pm 11.2$ & $60.4 \pm 9.5$ & 0.70 & 0.45 \\
\hline Conjunctival redness in nasal limbs & $1.26 \pm 0.39$ & $\mathrm{I} .3 \mathrm{I} \pm 0.53$ & $1.18 \pm 0.54$ & $1.19 \pm 0.45$ & 0.13 & 0.90 \\
\hline Conjunctival redness in the temporal limbs & $1.29 \pm 0.35$ & $1.44 \pm 0.32$ & $1.25 \pm 0.41$ & $1.35 \pm 0.37$ & 0.23 & 0.91 \\
\hline
\end{tabular}

Notes: All P-values were calculated using a generalized estimating equation model.

Abbreviations: MG, meibomian gland; MGD, meibomian gland dysfunction; NIBUT, non-invasive tear break-up time; OSDI, ocular surface disease index; SD, standard deviation; TMH, tear meniscus height. 


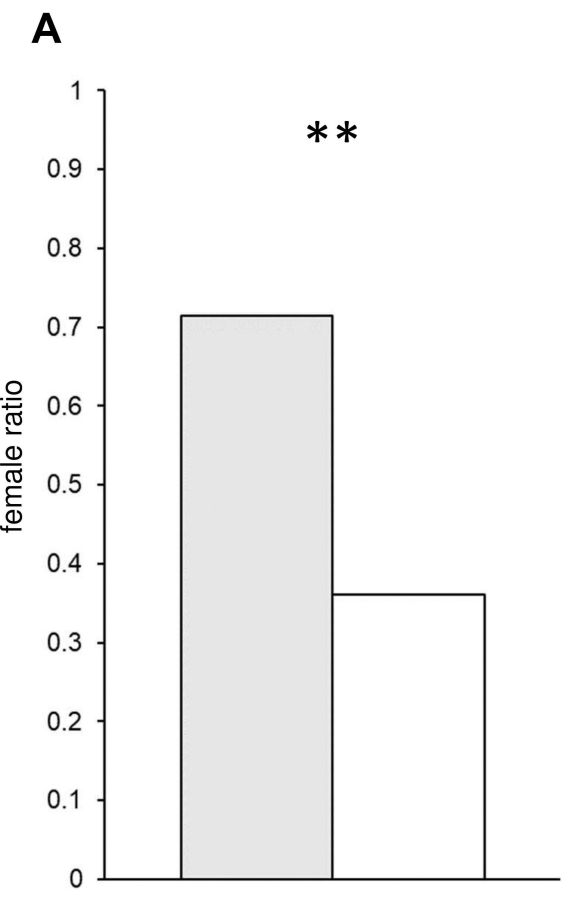

B

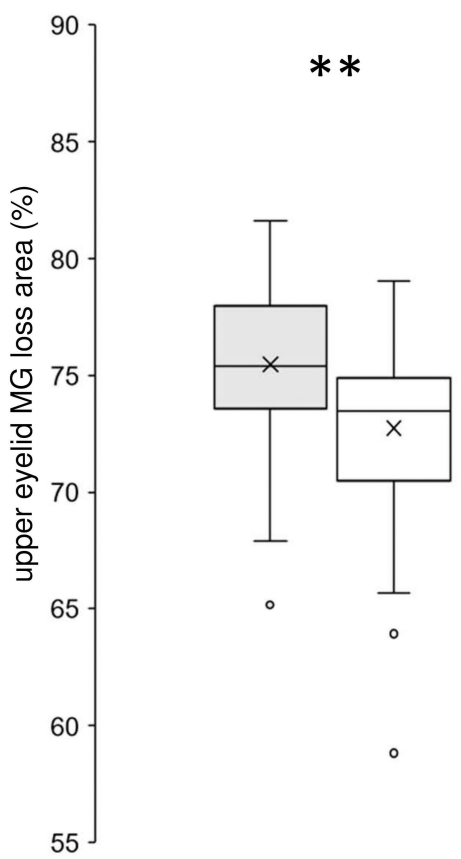

C

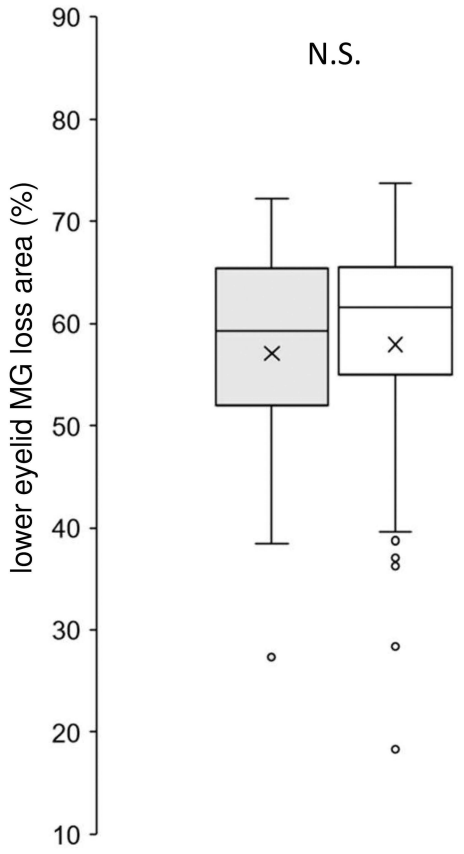

Figure 2 Baseline and preoperative ocular parameters in eyes with or without cataract surgery-induced DE symptoms. The representative baseline and preoperative ocular parameters, female ratio (A), upper eyelid MG loss area (\%) (B), lower eyelid MG loss area (\%) (C), are presented. The horizontal lines in the box and whisker plots represent the median values, and the bottom and top of the boxes represent the lower and upper quartiles, respectively. The $x$ represents the mean and the bars represent the minimum and maximum values within 1.5 times the lower and upper quartiles. ( ${ }^{* *} \mathrm{P}<0.0 \mathrm{I}$, generalized estimating equation models).

Abbreviations: MG, meibomian gland; TMH, tear meniscus height; OSDI, ocular surface disease index.

The preoperative and postoperative ocular parameters of the two groups are shown in Table 2. Among the preoperative baseline parameters, upper eyelid MG loss area was significantly greater in the eyes with cataract surgery-induced subjective DE symptoms than in the eyes without cataract surgery-induced subjective DE symptoms $(P<0.05$, GEE; Table 2, Figure 2B), but the lower eyelid MG loss area was not significant (Figure 2C). Among the 1-month postoperative parameters, the decreased meibum expressibility score was significantly greater in the eyes with cataract surgery-induced subjective DE symptoms than in those without cataract surgery-induced subjective DE symptoms, whereas the TMH was significantly smaller $(P<0.05$, GEE; Table 2$)$.

\section{Risk Factors for Cataract Surgery-Induced DE Symptoms}

We performed multivariable logistic regression analyses with GEE using background parameters including age, sex, and ocular parameters at baseline and 1 month postoperatively to assess the risk factors for cataract surgery-induced subjective DE symptoms (OSDI $>0$ at 1 month postoperatively).

Among the baseline preoperative and 1-month postoperative parameters, the baseline upper eyelid MG loss area (\%) (odds ratio $[\mathrm{OR}] 6.72, \mathrm{P}=0.012)$ and female sex $(\mathrm{OR} 4.20, \mathrm{P}=0.037)$ were statistically significant.

\section{Discussion}

This observational study investigated the influence of cataract surgery on the ocular surface in the early postoperative phase, specifically its impact on subjective DE symptoms in completely preoperatively symptom-free patients, by comparing the prevalence of DE before and after surgery. In previous studies, some portion of the eyes with DE before 
cataract surgery healed after surgery. ${ }^{11}$ Thus we included the patients without any preoperative DE symptoms $(\mathrm{OSDI}=0)$ and $\mathrm{DE}$ treatment in order to investigate clearly the risk factors for postoperative DE induced by cataract surgery in subjectively healthy patients. The incidence of after surgery subjective DE symptom (OSDI $>0$ ) in previously non-DE symptom patients was 21 out of 82 eyes (25.6\%). It was confirmed that cataract surgery shortened BUT and increased the fluorescein ocular surface staining score. Moreover, the significant and detectable risk factors for subjective DE symptom development following cataract surgery were the preoperative upper eyelid MG loss area (\%) and female sex.

Possible mechanisms of DE induction following cataract surgery have been proposed, including incisional corneal nerve damage. ${ }^{26}$ The temporal Incision can disrupt the corneal nerve plexus and possibly affect the dryness of the ocular surface. ${ }^{27}$ Other proposed factors were ocular surface damage owing to the toxic effects of eye drops (povidone-iodine, ${ }^{28}$ topical anesthetic ophthalmic solution, ${ }^{29}$ and preservatives ${ }^{30}$ ), repeated intraoperative ocular surface drying and irrigation, ${ }^{31}$ and phototoxicity. ${ }^{32}$ However, a multi-center study reported that the incision position and width, disinfection drug, anesthesia, surgery time, and preoperative Schirmer test were not significant risk factors. ${ }^{12}$

A previous study examined the MGD involvement in DE development following cataract surgery and reported lower eyelid MGD to be a prominent risk factor, with an OR of 1.145, but did not examine the upper eyelid. ${ }^{23}$ This study demonstrated that the monitoring of upper eyelid meibography before cataract surgery and intervention in addition to lower eyelid meibography, when necessary, could help avoid DE symptoms induced by surgery, and that the involvement of the upper eyelid MG is stronger than the lower eyelid MG. In our study, patients without subjective DE symptoms before surgery were selected; thus, it is suggested that the potential risk for DE symptoms onset following cataract surgery should be considered with care, ${ }^{33}$ and meibography preoperative examination in terms of tear film dynamics should be considered. ${ }^{34,35}$ Patients with any of these risk factors, in addition to those previously reported in an epidemiological study of DE in the elderly Japanese population, ${ }^{36}$ should be expected to encounter postoperative DE, and appropriate countermeasures should be considered. ${ }^{37}$

The persistence of moderate-level inflammation has been reported in MG dysfunction, such as during soft contact lens use; inflammatory cytokines, such as MMP-9, were observed. ${ }^{38}$ In cataract surgery, inflammation induction is inevitable; thus, further evaluation of the lacrimal fluid, including cytokines, would be useful.

In addition, ocular rosacea is the underlying cause of some of the items, such as vascularity of the lid margin (telangiectasia), ${ }^{39}$ for MG dysfunction diagnosis, defined by the international workshop on MG dysfunction. ${ }^{37}$ In our study, ocular rosacea related telangiectasia and conjunctival redness in the temporal limbs increased after surgery; however, they did not serve as risk factors for after surgery subjective DE symptom.

The main limitation of the present study is the retrospective design and the small sample size. Our results need to be verified with a prospective, randomized, masked study in the future. The data here suggest that examining a large cohort of patients, with and without DE, is important to confirm the risk factors of cataract surgery-induced DE symptoms.

\section{Conclusions}

The subjective DE symptom onset following cataract surgery was associated with the baseline upper eyelid MG loss before surgery and female sex. Clinicians should monitor these parameters before and after cataract surgery. Careful and active DE management of patients with high-risk factors following cataract surgery may be needed to prevent DE symptoms and ensure patient satisfaction.

\section{Abbreviations}

BUT, break-up time; DE, dry eye; GCP, good clinical practice; MG, meibomian gland; NIBUT, non-invasive tear breakup time; OR, odds ratio; OSDI, ocular surface disease index; TMH, tear meniscus height.

\section{Data Sharing Statement}

The data that support the findings of this study are available from the corresponding author H.F. upon reasonable request. 


\section{Ethics Approval and Informed Consent}

The study was approved by the Institutional Review Board of Kawasaki Medical School Hospital (approval number 5441-00). Informed consent was obtained from all study participants. The study adhered to the tenets of the Declaration of Helsinki and was performed according to Good Clinical Practice (GCP).

\section{Consent for Publication}

Written informed consent was obtained from the patient for publication of this report and any accompanying images.

\section{Acknowledgments}

The funders had no role in study design, data collection and analysis, decision to publish, or preparation of the manuscript. The authors thank T. Baba, T. Yamashita, and Y. Ohashi for the discussions, advice, and criticism that greatly benefitted this project.

\section{Author Contributions}

All authors made a significant contribution to the work reported, whether that is in the conception, study design, execution, acquisition of data, analysis and interpretation, or in all these areas; took part in drafting, revising or critically reviewing the article; gave final approval of the version to be published; have agreed on the journal to which the article has been submitted; and agree to be accountable for all aspects of the work.

\section{Funding}

This research was funded in part by Research Project Grant R02B-010 from Kawasaki Medical School (to H.F.).

\section{Disclosure}

Hisataka Fujimoto reports grants from Alcon, Otsuka, Kowa, Santen, and Novartis. Shintaro Ochi reports grants from Santen. Yasushi Inoue reports grants from Santen, Junichi Kiryu, Kowa, Alcon, Novartis, and Otsuka. The authors report no other conflicts of interest in this work.

\section{References}

1. Li XM, Hu L, Hu J, Wang W. Investigation of dry eye disease and analysis of the pathogenic factors in patients after cataract surgery. Cornea. 2007;26(9)(suppl1):S16-S20.

2. Hwang HB, Kim HS. Phototoxic effects of an operating microscope on the ocular surface and tear film. Cornea. 2014;33(1):82-90. doi:10.1097/ ICO.0000000000000001

3. Simone JN, Whitacre MM. Effects of anti-inflammatory drugs following cataract extraction. Curr Opin Ophthalmol. 2001;12(1):63-67. doi:10.1097/00055735-200102000-00011

4. Kasetsuwan N, Satitpitakul V, Changul T, Jariyakosol S, Wedrich A. Incidence and pattern of dry eye after cataract surgery. PLoS One. 2013;8(11): e78657. doi:10.1371/journal.pone.0078657

5. Kim JH, Chung JL, Kang SY, Kim SW, Seo KY. Change in corneal sensitivity and corneal nerve after cataract surgery. Cornea. 2009;28(11):S20S25. doi:10.1097/ICO.0b013e3181aea0e3

6. Bron AJ, Tiffany JM. The contribution of meibomian disease to dry eye. Ocul Surf. 2004;2(2):149-165.

7. Han KE, Yoon SC, Ahn JM, et al. Evaluation of dry eye and meibomian gland dysfunction after cataract surgery. Am J Ophthalmol. 2014;157 (6):1144-1150.e1. doi:10.1016/j.ajo.2014.02.036

8. Cetinkaya S, Mestan E, Acir NO, Cetinkaya YF, Dadaci Z, Yenere HI. The course of dry eye after phacoemulsification surgery. Tinkaya S. BMC Ophthalmol. 2015;15:68. doi:10.1186/s12886-015-0058-3

9. Jiang D, Xiao X, Fu T, Mashaghi A, Liu Q, Hong J. Transient tear film dysfunction after cataract surgery in diabetic patients. PLoS One. 2016;11 (1):e0146752. doi:10.1371/journal.pone.0146752

10. Park Y, Hwang HB, Kim HS, Wedrich A. Observation of influence of cataract surgery on the ocular surface. PLoS One. 2016;11(10):e0152460. doi:10.1371/journal.pone.0152460

11. Miyake K, Yokoi N. Influence on ocular surface after cataract surgery and effect of topical diquafosol on postoperative dry eye: a multicenter prospective randomized study. Clin Ophthalmol. 2017;11:529-540. doi:10.2147/OPTH.S129178

12. Maruyama K, Yokoi N, Takamata A, Kinoshita S. Effect of environmental conditions on tear dynamics in soft contact lens wearers. Invest Ophthalmol Vis Sci. 2004;45(8):2563-2568. doi:10.1167/iovs.03-1185

13. Chia EM, Mitchell P, Rochtchina E, Lee AJ, Maroun R, Wang JJ. Prevalence and associations of dry eye syndrome in an older population: the Blue Mountains Eye Study. Clin Exp Ophthalmol. 2003;31(3):229-232. doi:10.1046/j.1442-9071.2003.00634.x

14. Ong ES, Alghamdi YA, Levitt RC, et al. Longitudinal examination of frequency of and risk factors for severe dry eye symptoms in US veterans. JAMA Ophthalmol. 2016;2016:4925. doi:10.1001/jamaophthalmol 
15. Uchio M, Nishiwaki Y, Michikawa T, et al. Prevalence and risk factors of dry eye disease in Japan: Koumi study. Ophthalmology. 2011;118:2361-2367. doi:10.1016/j.ophtha.2011.05.029

16. Yamaguchi M, Kutsuna M, Uno T, et al. Marx line: fluorescein staining line on the inner lid as indicator of meibomian gland function. Am J Ophthalmol. 2006;141(4):669-675. doi:10.1016/j.ajo.2005.11.004

17. Shimazaki J. Definition and diagnostic criteria of dry eye disease: historical overview and future directions. Invest Ophthalmol Vis Sci. 2018;59(14): DES7-DES12. doi:10.1167/iovs.17-23475

18. Amano S, Inoue K. Clinic-based study on meibomian gland dysfunction in Japan. Invest Ophthalmol Vis Sci. 2017;58:2. doi:10.1167/iovs.16-21374

19. Vu CHV, Kawashima M, Yamada M, et al; Dry Eye Cross-Sectional Study in Japan Study Group. Influence of meibomian gland dysfunction and friction-related disease on the severity of dry eye. Ophthalmology. 2018;125(8):1181-1188. doi:10.1016/j.ophtha.2018.01.025

20. Amano S, Inoue K. Effect of topical 3\% diquafosol sodium on eyes with dry eye disease and meibomian gland dysfunction. Clin Ophthalmol. 2017;11:1677-1682. doi:10.2147/OPTH.S148167

21. Miller KL, Walt JG, Mink DR, et al. Minimal clinically important difference for the ocular surface disease index. Arch Ophthalmol. 2010;128 (1):94-101. doi:10.1001/archophthalmol.2009.356

22. Arita R, Suehiro J, Haraguchi T, Shirakawa R, Tokoro H, Amano S. Objective image analysis of the meibomian gland area. Br J Ophthalmol. 2014;98(6):746-755. doi:10.1136/bjophthalmol-2012-303014

23. Choi YJ, Park SY, Jun I, et al. Perioperative ocular parameters associated with persistent dry eye symptoms after cataract surgery. Cornea. 2018;37 (6):734-739. doi:10.1097/ICO.0000000000001572

24. Toyos R, Toyos M, Willcox J, et al. Evaluation of the safety and efficacy of intense pulsed light treatment with meibomian gland expression of the upper eyelids for dry eye disease. Photobiomodul Photomed Laser Surg. 2019;37(9):527-531. doi:10.1089/photob.2018.4599

25. Zeger SL, Liang KY. Longitudinal data analysis for discrete and continuous outcomes. Biometrics. 1986;42:121-130. doi:10.2307/2531248

26. John T. Corneal sensation after small incision, sutureless, one-handed phacoemulsification. J Cataract Refract Surg. 1995;21(4):425-428. doi:10.1016/S0886-3350(13)80533-0

27. Sitompul R, Sancoyo GS, Hutauruk JA, et al. Sensitivity change in cornea and tear layer due to incision difference on cataract surgery with either manual small-incision cataract surgery or phacoemulsification. Cornea. 2008;27(suppl 1):S13-S18. doi:10.1097/ICO.0b013e31817f29d8

28. Apt L, Isenberg SJ, Yoshimori R, Spierer A. Outpatient topical use of povidone-iodine in preparing the eye for surgery. Ophthalmology. 1989;96 (3):289-292. doi:10.1016/S0161-6420(89)32897-1

29. Moreira LB, Kasetsuwan N, Sanchez D, Shah SS, LaBree L, McDonnell PJ. Toxicity of topical anesthetic agents to human keratocytes in vivo. $J$ Cataract Refract Surg. 1999;25(7):975-980. doi:10.1016/S0886-3350(99)00075-9

30. Jee D, Park M, Lee HJ, Kim MS, Kim EC. Comparison of treatment with preservative-free versus preserved sodium hyaluronate $0.1 \%$ and fluorometholone $0.1 \%$ eye drops after cataract surgery in patients with preexisting dry-eye syndrome. J Cataract Refract Surg. 2015;41 (4):756-763. doi:10.1016/j.jcrs.2014.11.034

31. He Y, Li J, Zhu J, Jie Y, Wang N, Wang J. The improvement of dry eye after cataract surgery by intraoperative using ophthalmic viscosurgical devices on the surface of cornea: the results of a consort-compliant randomized controlled trial. Medicine. 2017;96(50):e8940. doi:10.1097/ MD.0000000000008940

32. Cho YK, Kim MS. Dry eye after cataract surgery and associated intraoperative risk factors. Korean J Ophthalmol. 2009;23(2):65-73. doi:10.3341/ kjo.2009.23.2.65

33. Fujimoto H, Setoguchi Y, Kiryu J. The ROCK inhibitor ripasudil shows an endothelial protective effect in patients with low corneal endothelial cell density after cataract surgery. Transl Vis Sci Technol. 2021;10(4):18. doi:10.1167/tvst.10.4.18

34. Fujimoto H, Ochi S, Yamashita T, Inoue Y, Kiryu J. Role of the water gradient structure in inhibiting thin aqueous layer break in silicone hydrogel-soft contact lens. Transl Vis Sci Technol. 2021;10(11):5. doi:10.1167/tvst.10.11.5

35. Fujimoto H. Noninvasive measurement of tear film break-up time in eyes with high-water-content contact lenses. Kawasaki Med J. 2020;46:87-95.

36. Uchino M, Dogru M, Yagi Y, et al. The features of dry eye disease in a Japanese elderly population. Optom Vis Sci. 2006;83(11):797-802. doi:10.1097/01.opx.0000232814.39651.fa

37. Tomlinson A, Bron AJ, Korb DR, et al. The international workshop on meibomian gland dysfunction: report of the diagnosis subcommittee. Invest Ophthalmol Vis Sci. 2011;52(4):2006-2049. doi:10.1167/iovs.10-6997f

38. Alghamdi W, Markoulli M, Papas E. The relationship between tear film MMP-9 and meibomian gland changes during soft contact lens wear. Cont Lens Anterior Eye. 2020;43(2):154-158. doi:10.1016/j.clae.2019.07.007

39. Saá FL, Cremona F, Chiaradia P. Association between skin findings and ocular signs in rosacea. Turk J Ophthalmol. 2021;51(6):338-343. doi:10.4274/tjo.galenos.2021.05031

Clinical Ophthalmology

\section{Publish your work in this journal}

Clinical Ophthalmology is an international, peer-reviewed journal covering all subspecialties within ophthalmology. Key topics include: Optometry; Visual science; Pharmacology and drug therapy in eye diseases; Basic Sciences; Primary and Secondary eye care; Patient Safety and Quality of Care Improvements. This journal is indexed on PubMed Central and CAS, and is the official journal of The Society of Clinical Ophthalmology (SCO). The manuscript management system is completely online and includes a very quick and fair peer-review system, which is all easy to use. Visit http://www. dovepress.com/testimonials.php to read real quotes from published authors.

Submit your manuscript here: https://www.dovepress.com/clinical-ophthalmology-journal 